\title{
AOR
}

Selected Papers of \#AolR2021:

The 22nd Annual Conference of the Association of Internet Researchers Virtual Event / 13-16 Oct 2021

\section{LEARNING IN/DEPENDENTLY IN REFUGEE CAMPS: COMMUNITY- BASED PERSPECTIVES ON TEACHING, LEARNING, AND TECHNOLOGY}

\author{
Negin Dahya \\ University of Toronto \\ Cansu Ekmekcioglu \\ University of Toronto \\ Olivier Arvisais \\ Université du Québec à Montréal (UQAM) \\ Laurie Decarpentrie \\ Université du Québec à Montréal (UQAM)
}

As the global COVID-19 pandemic persists, collecting qualitative research data in hard to reach settings remains fraught with challenges. Digital data collection and participatory research practices have become essential methodological tools to conduct qualitative research in places like the Dzaleka Refugee Camp in Malawi, where this study is based. This AolR paper will be framed around two key components of this work. The first pertains to the methods in place, specifically, participatory research methods in a digital data collection setting. The second area of focus will be on the preliminary findings from data collection underway between April-July 2021, based on the socio-technical exploration of teaching and learning with technology in Dzaleka.

There is an evident gap in relation to what we know about teaching, learning, and technology for refugee people in camps. The focus of this project is to understand the ways in which teaching, learning, and technology interact in/dependently in the daily lives of refugee people in Dzaleka at home, in the community, and at school. Distinctly, we are asking questions about the role of technology in the everyday lives of refugee people in Dzaleka, and specifically related to how teaching and learning relationships are enacted with, about, and around tools that are of value to community members. 
In recent years, the integration of technology into resource deprived communities like refugee camps has become more prevalent. Most notably, of course, is the near ubiquitous distribution and use of mobile phones and related internet enabled applications and software. The United Nations High Commissioner for Refugees has identified the importance of mobile phones in the lives of refugee people (UNHCR, 2016). UNHCR suggests that over $80 \%$ of refugees have access to mobile networks globally, and that number rises to $93 \%$ in urban areas. However, barriers to connectivity include unstable network connections, lack of access to electricity to charge phones, and inadequate literacy and digital literacy levels. These challenges are further complicated with multiple intersecting inequalities of age, race, gender, ability, socioeconomic situation, access to education and training. Important to note is that much of the content online is not available in local languages, making digital literacy additionally challenging.

Despite barriers and inconsistencies in access, studies have shown technology is prevalent in the context of migration, ranging from mobile phone usage to navigate the process of fleeing one country to seek asylum in another, to communicating with family and friends in diaspora, and using language learning apps in host countries (De Paepe et al., 2018). This landscape presents critical questions about how people experiencing forced migration are learning about technology and what technologies are in use.

At the higher education level, only $3 \%$ of refugees have access to formal education and many of these programs include online learning, especially over the past year. Mobiles are critical tools to support teachers and learners seeking formal education, and are being used to promote important gender equity initiatives (Dahya et al., 2019; Dahya \& Dryden-Peterson, 2017). There are some technology initiatives in classrooms but teachers have also described restrictions on the use of tools like mobiles as well (Dryden-Peterson et al., 2017). Only $77 \%$ of refugees access formal primary education and only $31 \%$ access secondary school (36\% of boys are enrolled in secondary school and $27 \%$ of girls). There are ample educational technology initiatives deployed in camps through humanitarian aid agencies and often in partnership with private and/or corporate partnerships (Lewis \& Thacker, 2016). For example, Menashy and Zakharia (2018) have identified that half of the funds that go to education to support the Syrian refugee crisis are focused on technology initiatives.

This reality around digital and mobile technology in refugee settings presents an educational paradox of sorts. Our inquiry explores how refugee people in camps learn to use technology and what technology is in use, including and beyond what is known about mobile phones. How are people learning independently, within the rich cultural landscape of Dzaleka, and dependently, drawing on international programs and resources - as well as everything in between?

Our research questions are:

(1) What types of technology are most prevalent in the camp, across women and men, and why? 
(2) What conditions - social, cultural, economic, geopolitical, educational - create meaningful and successful learning experiences with or about these tools?

(3) What pedagogical practices are adopted for, or emergent from, teaching with or about these tools in refugee camps, for women and men?

To understand this landscape, we are adopting Sarah Lawrence-Lightfoot's ethnographic methodology of portraiture (Lawrence-Lightfoot \& Davis, 1997). We are building on her approach and pairing it with participatory research practices and digital data collection methods. Our project began with recruitment of community researchers through our non-profit partner and using WhatsApp, asking for video submissions from interested applicants. In October 2020, we hired six community researchers, four men and two women, and began a five-month, online research training program.

Throughout our training process, including observation exercises and visual data collection activities, the team has agreed on three primary settings of research focus: (1) online learning; (2) music production and DJing; (3) sewing. Each of these settings has been described by and discussed with the community researchers as richly integrated with technology teaching and learning in both formal and informal ways. Our findings shed light on novel, in/dependent forms of teaching and learning in refugee camps. This work is needed to inform future technology initiatives in those settings from a community-based perspective.

\section{References}

Dahya, N., \& Dryden-Peterson, S. (2017). Tracing pathways to higher education for refugees: The role of virtual support networks and mobile phones for women in refugee camps. Comparative Education, 53(2), 284-301. https://doi.org/10.1080/03050068.2016.1259877

Dahya, N., Dryden-Peterson, S., Douhaibi, D., \& Arvisais, O. (2019). Social support networks, instant messaging, and gender equity in refugee education. Information, Communication \& Society, 22(6), 774-790. https://doi.org/10.1080/1369118X.2019.1575447

De Paepe, L., Zhu, C., \& Depryck, K. (2018). Online Dutch L2 learning in adult education: Educators' and providers' viewpoints on needs, advantages and disadvantages. Open Learning: The Journal of Open, Distance and e-Learning, 33(1), 18-33. https://doi.org/10.1080/02680513.2017.1414586

Dryden-Peterson, S., Dahya, N., \& Douhaibi, D. (2017, March 14). How teachers use mobile phones as education tools in refugee camps. Brookings. https://www.brookings.edu/blog/education-plus-development/2017/03/14/howteachers-use-mobile-phones-as-education-tools-in-refugee-camps/ 
Lawrence-Lightfoot, S., \& Davis, J. H. (1997). The art and science of portraiture (1st ed). Jossey-Bass.

Lewis, K., \& Thacker, S. (2016). ICT and the Education of Refugees: A Stocktaking of Innovative Approaches in the MENA Region. SABER-ICT Technical Paper Series;No. 17. World Bank, Washington, DC. https://openknowledge.worldbank.org/handle/10986/26522

UNHCR. (2016). Connectivity for Refugees. https://www.unhcr.org/innovation/wpcontent/uploads/2018/02/20160707-Connecting-Refugees-Web_withsignature.pdf

Zakharia, Z., \& Menashy, F. (2018). Private participation in the education of Syrian refugees: Understanding the roles of businesses and foundations. In G. SteinerKhamsi \& A. Draxler (Eds.), The State, Business and Education (pp. 52-67). Edward Elgar Publishing. https://doi.org/10.4337/9781788970334.00009 